\title{
Fate of Lu(III) sorbed on 2-line ferrihydrite at pH 5.7 and aged for 12 years at room temperature. II
}

DOI:

10.1007/s11356-018-1904-7

\section{Document Version}

Accepted author manuscript

Link to publication record in Manchester Research Explorer

\section{Citation for published version (APA):}

Yokosawa, T., Prestat, E., Polly, R., Bouby, M., Dardenne, K., Finck, N., Haigh, S. J., Denecke, M. A., \& Geckeis, $\mathrm{H}$. (2018). Fate of Lu(III) sorbed on 2-line ferrihydrite at $\mathrm{pH} 5.7$ and aged for 12 years at room temperature. II: insights from STEM-EDXS and DFT calculations. Environmental Science and Pollution Research, 1-12. https://doi.org/10.1007/s11356-018-1904-7

\section{Published in:}

Environmental Science and Pollution Research

\section{Citing this paper}

Please note that where the full-text provided on Manchester Research Explorer is the Author Accepted Manuscript or Proof version this may differ from the final Published version. If citing, it is advised that you check and use the publisher's definitive version.

\section{General rights}

Copyright and moral rights for the publications made accessible in the Research Explorer are retained by the authors and/or other copyright owners and it is a condition of accessing publications that users recognise and abide by the legal requirements associated with these rights.

\section{Takedown policy}

If you believe that this document breaches copyright please refer to the University of Manchester's Takedown Procedures [http://man.ac.uk/04Y6Bo] or contact uml.scholarlycommunications@manchester.ac.uk providing relevant details, so we can investigate your claim.

\section{OPEN ACCESS}


Fate of Lu(III) sorbed on 2-line ferrihydrite at pH 5.7 and aged for 12 years at room temperature.

\title{
II: Insights from STEM-EDXS and DFT calculations
}

\author{
Tadahiro Yokosawa, ${ }^{\mathrm{a}, 1,{ }^{*}}$, Eric Prestat ${ }^{\mathrm{b}}$, Robert Polly ${ }^{\mathrm{a}}$, Muriel Bouby, ${ }^{\mathrm{a}, *}$, Kathy Dardenne ${ }^{\mathrm{a}}$, \\ Nicolas Finck ${ }^{\mathrm{a}}$, Sarah J. Haigh ${ }^{\mathrm{b}}$, Melissa A. Denecke ${ }^{\mathrm{c}}$, and Horst Geckeis ${ }^{\mathrm{a}}$
}

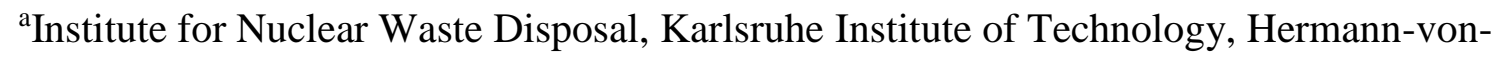
Helmholtz-Platz 1, D-76344 Eggenstein-Leopoldshafen, Germany.
\end{abstract}

(tadahiro.yokosawa@fau.de, polly@kit.edu, muriel.bouby@kit.edu, kathy.dardenne@kit.edu, nicolas.finck@kit.edu, horst.geckeis@kit.edu)

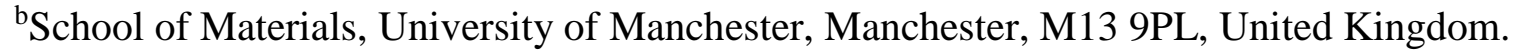 (eric.prestat@manchester.ac.uk, sarah.haigh@manchester.ac.uk)

'Dalton Nuclear Institute, University of Manchester, Manchester M13 9PL, United Kingdom. (melissa.denecke@manchester.ac.uk)

\footnotetext{
*Corresponding authors: tadahiro.yokosawa@fau.de (T. Yokosawa), muriel.bouby@kit.edu (M. Bouby)

${ }^{1}$ Present address: Institute of Micro- and Nanostructure Research, Friedrich-AlexanderUniversität Erlangen-Nürnberg, Cauerstraße 6, 91058 Erlangen, Germany.
}

\section{Keywords}

2-line ferrihydrite, Lutetium, Transformation products, Hematite, Goethite, Incorporation, STEM-EDXS, DFT. 


\section{Abstract}

Transformation products of 2-line ferrihydrite associated with Lu(III) were studied after 12 years of aging using aberration corrected high-angle annular dark field scanning transmission electron microscopy (HAADF-STEM), high efficiency energy dispersive X-ray spectroscopy (EDXS) and density functional theory (DFT). The transformation products consisted of hematite nanoparticles with overgrown goethite needles. High efficiency STEM-EDXS revealed that Lu is only associated with goethite needles, and atomic resolution HAADF-STEM reveals structural incorporation of Lu within goethite, partially replacing structural Fe sites. This finding corroborates those recently obtained by AsFlFFF and EXAFS spectroscopy on the same sample (Finck et al. 2018). DFT calculations indicate that Lu incorporation within goethite or hematite are almost equally likely, suggesting that experimental parameters such as temperature and reaction time which affect reaction kinetics, play important roles in determining the Lu uptake. It seems likely that these results may be transferable to predict the behavior of chemically homologous trivalent actinides.

\section{Introduction}

Iron (hydr)oxides are widespread in nature and can play an important role in the bioavailability and migration of environmental pollutants, such as heavy metal ions or radionuclides (RNs) (Raiswell 2011; Baleeiroa et al. 2018). Iron (hydr)oxides will also form upon steel canister corrosion in the near field of a high-level nuclear waste repository, thus representing an additional barrier to the RNs' migration to the far field. Ferrihydrite is a hydrous ferric oxide that is poorly ordered and usually exists as a fine grained nanoparticulate with high surface area (Cornell and Schwertmann 1996), allowing it to interact substantially with pollutants present in aqueous environments (Michel et al. 2007; Xiu et al. 2018). However, it is thermodynamically unstable and during aging will transform into more stable oxides, such as hematite or goethite, with the nature of the transformation product depending on the environmental conditions. The interaction of RNs with pre-formed ferrihydrite will immobilize these species or retard their migration, either by surface adsorption and/or by structural incorporation (Denecke 2006; Novikov et al. 2006; Geckeis et al. 2013; O'Loughlin et al. 2003; Duff et al. 2002; Latta et al. 2012; Marshall et al. 2014; Finck et al. 2018; Xiu et al. 2018). However, there is a risk that ferrihydrite immobilized RNs can potentially be released upon the ferrihydrite's transformation to hematite or goethite. Consequently, in order to be considered as a stable RNs immobilization mechanism, information on the fate of RNs immobilized by 
metastable ferrihydrite upon aging is of crucial importance (Tan et al. 2010). In general, changes in the composition of mineral phases occur in the presence of water and are usually slow processes in low temperature systems (Gorski and Fantle 2017). The use of samples aged for long periods are thus essential for determining whether structural immobilization is stable on the long-term or not.

Previous investigations using either the actinide Am(III) (Stumpf et al. 2006) or the lanthanide Lu(III) (Dardenne et al. 2001) reported the formation of bidentate surface species upon contact with pre-existing ferrihydrite in suspension, meaning that this lanthanide can be used as non-radioactive chemical homologue for trivalent actinides. The fate of $\mathrm{Lu}(\mathrm{III})$ sorbed onto pre-formed ferrihydrite upon aging in suspension at $70^{\circ} \mathrm{C}$ was investigated by microscopic and spectroscopic techniques (Dardenne et al. 2002). X-ray diffraction and infrared spectroscopy data have indicated a progressive transformation of ferrihydrite into a mixture of hematite and goethite, while X-ray absorption spectroscopy (XAS) data showed that Lu(III) progressively enters structural sites of hematite within a reaction time of only 238 hours (Dardenne et al. 2002; Bouby et al. 2004).

As the size of the hematite and goethite particles can be just a few nanometers (Cornell and Schwertmann 1996), they deserve particular attention as they can be highly mobile in the environment. For such small particles, transmission electron microscopy (TEM) is the technique of choice for their characterization with high spatial resolution. In general, TEM combined with spectroscopic methods, such as energy dispersive X-ray spectroscopy (EDXS) and/or electron energy loss spectroscopy (EELS), is applied in order to obtain elemental information as well as particle size, morphological and crystal structure information for individual nanoparticles (Utsunomiya and Ewing 2003; Brydson et al. 2014). However, it is challenging to detect and locally analyze trace elemental levels ( $\sim .1$ atom \%) for nanoparticles (Brydson et al. 2014), especially for electron beam sensitive materials, such as goethite (Cornell et al. 1983, Um et al. 2011). In order to acquire sufficient signal-to-noise ratios, high beam currents are required and this increases the likelihood of beam-induced specimen damage. High resolution TEM (HRTEM) is a powerful method to obtain structural information at the atomic scale but cannot directly yield elemental information because the image contrast is dominated by interference of electron wave scattered through the specimen. High-angle annular dark field STEM (HAADF-STEM) is an alternative imaging approach where the contrast scales directly with atomic number (Nellist and Pennycook 1999), making it especially useful for detecting heavy elements in a lighter matrix material (Powell et al. 2011). 
During the last decade, the X-ray detection efficiency of EDXS and the spatial resolution in STEM have dramatically improved through the development of high efficiency EDXS detector systems (Schlossmacher et al. 2010; Suenaga et al. 2012) and spherical aberration correctors which allow high currents to be focused into a small electron probe (Batson et al. 2002; Varela et al. 2005). High efficiency EDXS detection helps to provide sufficient X-ray signal while minimizing electron beam exposure of the specimen. Probe-side aberration corrected HAADF-STEM imaging further improves the detection of individual heavy element atoms in lighter matrices (Okuno et al. 2010) and this capability is exploited in this study to provide detailed insight into the interaction of trace level heavy elements with nanoparticle phases. To the best of the author's knowledge, this is the first time that aberration-corrected HAADF-STEM has been applied to study An/Ln incorporation into hematite/goethite systems.

Density functional theory (DFT) (Kohn and Sham 1964; Hohenberg 1964) using periodic boundary conditions has evolved into a well-established theoretical tool for the investigation of solid states. DFT provides theoretical structural information, which complements experimental data, e.g. XAS, as well as additional information, like reaction energies, that are experimentally more difficult to access (Skomurski et al. 2010; Smith et al. 2015). In this investigation theoretical studies were performed in order to determine whether Lu(III) is incorporated within hematite or in goethite nanoparticles.

In this study, 2-line ferrihydrite was aged for 12 years under ambient conditions in the presence of $\mathrm{Lu}$ (III) leading to its transformation into hematite and goethite. The largest particles of the aged solid were separated from the aqueous phase by centrifugation and the structural environment of $\mathrm{Lu}(\mathrm{III})$ ions in an isolated individual hematite nanoparticle and goethite needle from the supernatant was characterized by aberration corrected HAADF-STEM and high efficiency STEM-EDXS. Similar reported studies have typically only considered much shorter aging times (Dardenne et al. 2002; Finck et al. 2009), probed larger volume of samples by application of e.g. XAS and did not confront experimental data with theoretical calculations. XAS is an element specific technique and the recorded spectrum corresponds to contributions from all probed atoms. Consequently, if the sample contains probed atoms located in different binding environments the resulting spectrum corresponds to the sum of these contributions, which makes difficult to single out each individual contribution. The aim of this study was to apply advanced experimental and theoretical characterization techniques to investigate the long-term stability of the bound species and to corroborate data acquired for single particles with results from experimental techniques probing larger amounts of samples (Finck et al. 2018). 


\section{Materials and methods}

\subsection{Sample preparation}

The sample was prepared at room temperature with ultra-pure water (18.2 M $\Omega . c m$, Milli-Q system (Millipore)) and reagents of ACS grade or higher. An aqueous suspension of 2-line ferrihydrite was freshly synthesized according to (Schwertmann and Cornell 1991). The suspension had a mass concentration of $2.7 \mathrm{~g} / \mathrm{L}$ and was spiked by addition of $\mathrm{Lu}(\mathrm{III})$ ions $\left([\mathrm{Lu}(\mathrm{III})]=1.6 \times 10^{-4} \mathrm{~mol} / \mathrm{L}\right)$ under stirring. The $\mathrm{pH}$ was adjusted to $\sim 6$ and the suspension left to age under air and at room temperature in the dark for 12 years. After this reaction time, the suspension was centrifuged and solution chemistry indicated that about half of total Lu was associated with the settled solid phase and X-ray diffraction indicated that this solid phase consisted of a mixture of hematite and goethite (Finck et al. 2018). A TEM specimen was prepared from a suspension of the separated solid phase in ethanol, by dispersing it onto a carbon thin film on a Mo support grid. The Mo grid was used instead of the more common $\mathrm{Cu}$ grid support in order to avoid overlapping X-ray peaks for $\mathrm{Cu} K$ and $\mathrm{Lu} L$ in the EDX spectra. Particle size distributions obtained by TEM are shown in the Supporting Information (Figure $\mathrm{S} 1)$.

Atomic resolution HAADF-STEM and high efficiency EDXS were performed by using an aberration corrected FEI Titan G2 80-200 S/TEM "ChemiSTEM "TM" instrument operated at 200 $\mathrm{kV}$ with probe currents of $\sim 1300 \mathrm{pA}$ and $150 \mathrm{pA}$, respectively. This system can be regarded as a high efficiency EDXS system because it consists of 4 silicon drift detectors (SDD) built into the polepiece of the primary objective lens, which provides about five times higher X-ray detection efficiency ( $\sim 0.7 \mathrm{sr}$ total solid angle) than a conventional EDX system using a single $\mathrm{Si}(\mathrm{Li})$ detector (Schlossmacher et al. 2010). Moreover, the SDD also have a high maximum count rate, which allowed fast multiple scanning over the same area and the cumulative EDX signal to be summed, in order to reduce the electron dose rate locally for an individual pixel (Newbury 2005). This system allowed spectrum images with high signal to noise ratio to be acquired in a relatively short measurement time, reducing the potential for electron beam damage (Figures S2 and S3). The sample was mounted in a FEI double-tilt low background specimen holder, which provides high visibility of the specimen to the EDX detector. EDX data were acquired at $0^{\circ}$ tilt. Conventional (not high efficiency, $\sim 0.17 \mathrm{sr}$ solid angle) EDXS was performed using a FEI Tecnai G2 F20 X-TWIN operated at $200 \mathrm{kV}$. Background-subtracted EDX spectra were analyzed using the Cliff-Lorimer method without absorption correction in 
the Bruker Esprit software. HAADF-STEM images were acquired using a Fischione ADF detector and the inner and outer collection angles were 60 and $180 \mathrm{mrad}$, respectively. The convergence angle was set to $25 \mathrm{mrad}$. Image analysis was performed using Digital Micrograph. The lattice parameters of hematite and goethite used in this study are based on reported crystallographic data (Maslen et al. 1994, Hazemann et al. 1991). HAADF-STEM simulations have been performed using the QSTEM software package. The same convergence angles and inner/outer ADF detector angles as those of the experiments have been used for simulation.

\subsection{Theoretical methods}

The experimental efforts were complemented by DFT calculations with periodic boundary conditions as implemented in the Vienna Ab initio Simulation Package (VASP) (Kresse and Hafner 1993, Kresse and Furthmüller 1996a; Kresse and Furthmüller 1996b). The Kohn-Sham equations were solved using a plane-wave basis set. Electron exchange and correlation were described using the Perdew-Burke-Ernzerhof (PBE) version (Perdew et al. 1996) of the generalized gradient approximation (GGA). The ion cores were described by projector augmented wave (PAW) potentials (Blöchl 1994) implemented by Kresse and Joubert (Kresse and Joubert 1999). As shown by Rollmann et al. (Rollmann et al. 2004), the adequate theoretical framework for the description of hematite is DFT+U. The $\mathrm{U}$ parameter suggested for Fe by Wenzel and Steinle-Neumann (Wenzel and Steinle-Neumann 2007) was used in this study (U $=4.6, \mathrm{~J}=0.544)$. For $\mathrm{Lu}$ we circumvented the use of an additional $\mathrm{U}$ parameter by placing the 4f electrons in the core. A corresponding PAW for Lu doing just this is available in VASP.

An energy cutoff of $600 \mathrm{eV}$ was employed in this study for the kinetic energy of the plane waves for all calculations determining the lattice parameters for bulk phase and the positions of the ions. The first step was to determine the lattice parameters of the bulk phase for both hematite and goethite. For the initial relaxation of the structures, the real-space evaluation of the PAW projection operators (Kresse et al. 2016) was used. The lattice parameters were calculated by looping over the volume and relaxing the positions of the ions and optimizing the cell shape. The relaxation was stopped when the force on each atom was below $0.01 \mathrm{eV} / \AA$. For all calculations $3 \times 3 \times 3 k$-points were used. The optimized bulk structures of pure hematite and goethite served as base for further theoretical exploration of the $\mathrm{Lu}$ (III) incorporation into hematite and goethite. For the study of the Lu(III) incorporation into both iron phases a $2 \times 2 \times 2$ supercell containing $32 \mathrm{Fe}$ (III) ions was used in both cases. For hematite additional 48 oxygen ions and for goethite additional 64 oxygen and 32 hydrogen ions were used. The equal number 
of iron ions for both minerals simplifies the theoretical efforts in determining the changes upon replacing one $\mathrm{Fe}(\mathrm{III})$ ion by one $\mathrm{Lu}(\mathrm{III})$ ion.

In a last step, the optimized structures were used to determine the reaction energies of:

$$
(\text { Iron oxide } / \mathrm{Fe})+\mathrm{Ln}(\mathrm{III})\left(9 \mathrm{H}_{2} \mathrm{O}\right) \rightarrow(\text { Iron oxide } / \mathrm{Ln})+\mathrm{Fe}(\mathrm{III})\left(9 \mathrm{H}_{2} \mathrm{O}\right)(\mathrm{Ln}=\mathrm{La}, \mathrm{Gd}, \mathrm{Lu})
$$

Reaction energies calculated from the electronic energies of the optimized systems were considered as a reasonably good approximation for the Gibbs free energy $\Delta \mathrm{G} \sim \Delta \mathrm{E}$. Hence, in addition to the structures of the iron oxide and the iron oxides incorporating $\mathrm{Ln}^{3+}$, the structures of $\mathrm{La}^{3+}\left(9 \mathrm{H}_{2} \mathrm{O}\right), \mathrm{Gd}^{3+}\left(9 \mathrm{H}_{2} \mathrm{O}\right), \mathrm{Lu}^{3+}\left(8 \mathrm{H}_{2} \mathrm{O}\right)\left(\mathrm{H}_{2} \mathrm{O}\right)$ and $\mathrm{Fe}^{3+}\left(6 \mathrm{H}_{2} \mathrm{O}\right)\left(3 \mathrm{H}_{2} \mathrm{O}\right)$ have to be determined. $\mathrm{Lu}^{3+}\left(8 \mathrm{H}_{2} \mathrm{O}\right)\left(\mathrm{H}_{2} \mathrm{O}\right)$ and $\mathrm{Fe}^{3+}\left(6 \mathrm{H}_{2} \mathrm{O}\right)\left(3 \mathrm{H}_{2} \mathrm{O}\right)$ have only 8 and 6 water molecules present in the first coordination shell and therefore more water molecules were added in the second coordination shell to keep the number of water molecules constant throughout $(n=9)$. The structural optimization was carried out with DFT(BP86/TZVPP) using TURBOMOLE (TURBOMOLE 2015; Treutler and Ahlrichs 1995; Eichkorn et al. 1997; Eichkorn et al. 1995; Deglmann et al. 2004; Arnim and Ahlrichs 1999; Schäfer et al. 1992) followed by an optimization with VASP to provide a methodological homogeneous treatment. For the VASP calculations, we used large boxes, so the hydration complexes are well separated from their mirror images. The electronic energies were determined with these subsequent VASP calculations and used in turn to determine the reaction energies of eq. (1).

\section{Results and discussion}

\subsection{High efficiency STEM-EDXS}

Figure 1a shows a HAADF-STEM image of rhombohedral and acicular needle-shaped particles corresponding to hematite $\left(\alpha-\mathrm{Fe}_{2} \mathrm{O}_{3}\right)$ and goethite $(\alpha-\mathrm{FeOOH})$ crystals, respectively (Cornell and Schwertmann 1996; Schwertmann and Cornell 1991). Initially, conventional (not high efficiency) STEM-EDX spectrum imaging was performed on the hematite and goethite particles. To obtain sufficient X-ray signal, a high beam current (1.3 nA) and long pixel dwell time (4 sec) was necessary. However, the resulting data obtained from goethite nanoparticles could not be interpreted in a reliable way because the specimens were severely damaged and almost destroyed during data acquisition (Figure S2 in Supporting Information). Therefore, high efficiency STEM-EDX spectrum imaging was performed in order to obtain more reliable 
elemental analysis of individual particles. Figures 1b,c show such high efficiency STEM-EDX spectra obtained for the hematite particle and for the goethite particle shown in Figure 1a. The corresponding characteristic $\mathrm{X}$-rays from $\mathrm{O}$ and $\mathrm{Fe}$ are indicated in Figures 1b,c. The insets in Figures 1b,c depict enlarged views of the EDX spectra between 7 and $10 \mathrm{keV}$. The Lu $L$ lines (Lu $L_{\alpha}: 7.65 \mathrm{keV}$, Lu $L_{\beta}: 8.75 \mathrm{keV}$ ) are observed only in goethite, as indicated by arrowheads (Figure 1c). High efficiency STEM-EDX maps obtained from the area marked by the green square in Figure 1a are shown in Figure 2. Fe and $\mathrm{O}$ signals appear homogeneously distributed in both hematite and goethite, indicating that iron oxides are uniformly formed (Figure 2). On the other hand, the image shows clearly that Lu atoms are present predominantly in the goethite (Figure 2).

Quantitative analysis of the high efficiency STEM-EDX spectra show that the O/Fe ratios are 1.8 in hematite and 2.3 in goethite, close to those expected for hematite (1.5) and goethite (2.0). The Lu content in the goethite particle is approximately 0.3 at. $\%$, which is only just above the expected detection limit under the present experimental conditions ( $\sim .1$ at. \%) (Brydson et al. 2014). Therefore atomic resolution HAADF-STEM imaging was performed to further investigate the structure.

\subsection{Atomic resolution HAADF-STEM}

Atomic resolution HAADF-STEM imaging allows detection of individual heavy atoms in a lighter matrix as the contrast is highly sensitive to atomic number (Okuno et al. 2010; Voyles et al. 2002). The thinnest area of the goethite and hematite nanoparticles was imaged, as this is expected to provide the greatest signal to background ratio and hence the best opportunity to determine if $\mathrm{Lu}$ atoms are incorporated into the crystal structure.

Figure 3a shows a HAADF-STEM image obtained from a hematite particle oriented along the [100] zone-axis, as shown by the inset Fourier transform taken from the area indicated by a white square. The enlarged region in Figure $3 \mathrm{~b}$ shows the projection of pairs of Fe atomic columns (Maslen et al. 1994). The intensity profile (Figure 3c) taken across the atomic columns marked by the orange rectangle shows a homogeneous intensity profile with the expected lattice period of $\sim 0.27 \mathrm{~nm}$. All atomic columns have uniform intensity, with none showing the enhanced intensity that would be expected if heavy Lu atoms were incorporated into the lattice. Long-range intensity modulations at the scale of several nanometers can be attributed to thickness variation. In the area delimited by dotted lines (Figure $3 b$ ), a simulated HAADFSTEM image is overlaid to the experimental one. The simulation of a $7.9 \mathrm{~nm}$ thick hematite crystal along the [100] crystal shows good agreement with the experimental image. These 
results were consistent across many hematite particles studied and therefore it can be concluded that there is no Lu incorporation in the hematite nanoparticles.

HAADF-STEM imaging of the goethite gave very different results as shown in Figures 4a,b. The particle is viewed along the [001] direction and the position of the Fe atomic columns are indicated schematically by red circles in Figure $4 \mathrm{~b}$. In the thicker areas of the sample the atomic columns form a zigzag pattern, resulting in stripes in the image (Figure $4 \mathrm{~b}$ ) with a period of $0.496 \mathrm{~nm}$, which is also visible from the additional $\{100\}$ reflections seen in the Fourier transform of area A in (inset A of Figure 4a) (Hazemann et al. 1991). The absence of $\{100\}$ reflections in the thinner areas of the crystal (see inset B of Figure 4a) is a result of electron beam damage in goethite (Supporting Information Figure S4) (Cornell et al. 1983). However, unlike in hematite Figure $4 \mathrm{~b}$ shows the presence of isolated atomic columns with significantly higher intensity (indicated by the blue arrows in Figures $4 \mathrm{c}$,d). These brighter columns can be attributed to the presence of heavier atoms. A careful analysis of the intensity line profiles in Figure $4 \mathrm{~d}$ was able to exclude contributions from thickness variation or surface roughness. The intensity profile from the orange regions shows the typical intensity variation of the uniform matrix, while the blue region shows clear peaks of enhanced intensity such as would be expected for the inclusion of $\mathrm{Lu}$ in the goethite lattice. Importantly, the points of higher intensity are located at the same crystallographic sites as the Fe atomic columns, suggesting that $\mathrm{Lu}$ atoms are occupying Fe sites, and thus substitutionally incorporated in goethite (Figure 4d). Furthermore, the low contrast variation at the nanoscale in the area delimited by a red dotted line in Figure $4 \mathrm{c}$ implies that the thickness is homogeneous, supporting the interpretation of intensity variation in Figure $4 \mathrm{~d}$ being due to the presence of heavier atoms at Fe sites in the goethite lattice. A simulated HAADF-STEM image of a Lu atom substitutionally incorporated in a $5.6 \mathrm{~nm}$ thick goethite crystal is overlaid to the experimental image in the area delimited with a dashed line (Figure 4c). In the simulation, the brightest atomic column corresponds to the atomic column containing the substitutional Lu atom. Moreover, the simulated contrast of a substitutional $\mathrm{Lu}$ atom is in good agreement with experimental observations, confirming that the observed bright atomic columns are due to Lu incorporation. The evidence of $\mathrm{Lu}$ found in the goethite lattice but not in the hematite is consistent with EDXS results presented in the previous section, which demonstrated the presence of $\mathrm{Lu}$ associated with goethite crystals and not with hematite.

These results support those obtained recently by AsFIFFF and EXAFS spectroscopy on the same suspension (Finck et al. 2018), but they contrast somehow with earlier findings on 2LFh 
transformed upon tempering for $238 \mathrm{~h}$ at $70^{\circ} \mathrm{C}$ (Dardenne et al. 2002; Bouby et al. 2004). In these reported studies the $\mathrm{pH}$ decreased from $\sim 6$ to $\sim 4$ over the course of the transformation and a mixture of hematite and goethite formed, and XAS indicated a preferential Lu(III) incorporation within hematite rather than within goethite. Similarly, Nagano et al. reported the formation of pure goethite and $\mathrm{Nd}$-containing hematite upon aging at $70^{\circ} \mathrm{C}$ and $\mathrm{pH}>9$ ferrihydrite which was prepared in the presence of $\mathrm{Nd}(\mathrm{III})$ (Nagano et al. 1999). Furthermore, Stumpf et al. (2006) showed that the actinide Am(III) can be incorporated within transformation products upon ferrihydrite aging at $85^{\circ} \mathrm{C}$. However, these reported experiments were performed under different chemical conditions such as $\mathrm{pH}$ and temperature, thus leading to different immobilization mechanisms. For experiments with $\mathrm{Lu}(\mathrm{III})$, the differences in chemical conditions are likely to be the reason for the observed differences in the nature of the phase incorporating Lu upon ferrihydrite transformation (Finck et al. 2018).

In the present study, Lu(III) was contacted with pre-formed Fh in suspension and was almost quantitatively taken up as bidentate surface complex (Dardenne et al. 2001). In the aged sample, a fraction of the lanthanide was present in solution indicating a release from the surface upon transformation while the other fraction is structurally associated with transformation products. Ferrihydrite transformation proceeds through two competing mechanisms, dissolution and subsequent nucleation forming goethite and internal dehydration/rearrangement within $\mathrm{Fh}$ particles forming hematite. During the formation of goethite Lu(III) was released in solution and thus can only be incorporated within this phase upon nucleation or more likely during particle growth by e.g., oriented aggregation. A similar uptake mechanism by iron oxyhydroxide of $\mathrm{Cu}$ (II) has been reported recently (Stegemeier et al. 2015). Hematite formation proceeds through internal rearrangement within Fh having surface sorbed $\mathrm{Lu}(\mathrm{III})$, but data indicate that the lanthanide did not enter the crystal structure, or only in marginal amounts, implying a release in solution. The structure of hematite is made of $\mathrm{FeO}_{6}$ octahedra sharing edges and faces with neighboring octahedra, implying a more constrained Fe environment than in goethite where the structure is made of double bands of edge-sharing $\mathrm{FeO}_{3}(\mathrm{OH})_{3}$ octahedra linked by corner sharing (Schwertmann and Cornell 1991). Despite the larger size of Lu(III) compared to $\mathrm{Fe}$ (III), the lanthanide substitutes for structural Fe within goethite and may best be explained by adsorption at solid/liquid interface followed by overgrowth at room temperature. Elevated temperatures favor Fh dehydration and thus hematite formation. At the same time, hydration water molecules bound to Lu(III) may be more labile than at room temperature and the retention at the surface may be stronger because of larger sorption constants (Tertre et al. 
2006; Finck et al. 2008). All factors collectively favor structural uptake of Lu(III) by hematite at elevated temperature in contrast to room temperature.

\subsection{Results from DFT and DFT+U calculations}

To investigate the energetics of $\mathrm{Lu}(\mathrm{III})$ incorporation within hematite or goethite, DFT and $\mathrm{DFT}+\mathrm{U}$ calculations were carried out on the pure bulk phases, and DFT $+\mathrm{U}$ calculations for the case where one of the 32 iron ions (Fe(III)) in the supercell was replaced by one $\mathrm{Lu}(\mathrm{III})$ ion (Figure 5). Initially the structures of pure goethite and hematite were considered, as well as structural changes in hematite and goethite upon incorporation of $\mathrm{Lu}(\mathrm{III})$ and these results were compared with available experimental data in order to evaluate the quality and the reliability of the DFT and DFT+U results.

As can be seen in Table 1, the agreement between calculated structural data and experimental literature values for both bulk hematite and goethite is excellent and underpins the high quality of the DFT $+\mathrm{U}$ calculations. However, it is noticeable that for hematite the DFT $+\mathrm{U}$ results are in better match to experiment than the DFT results. Furthermore, the correct antiferromagnetic state of these minerals has been obtained. For the magnetic moments of the Fe(III) ions we obtain with DFT+U $4.2 \mu \mathrm{B}$ for both hematite and goethite which is in good agreement with previous theoretical reports (Rollmann et al. 2004, Tunega 2012). The agreement between calculated structural data and experiment for both solid phases upon replacing one $\mathrm{Fe}(\mathrm{III})$ ion by one $\mathrm{Lu}(\mathrm{III})$ ion was also good. In pure hematite the Fe-O distances calculated with $\mathrm{DFT}+\mathrm{U}$ are 197 and $212 \mathrm{pm}$.

The corresponding Lu-O distances in hematite determined with $\mathrm{DFT}+\mathrm{U}$ following the substitution of one Fe(III) by Lu(III) are 212 and 226 pm. Experimental data for Lu incorporated within hematite have been reported (Dardenne et al. 2002) and these agree very well with the calculated ones (Table 2). Averaging over the 212 and $226 \mathrm{pm}$ distances determined with $\mathrm{DFT}+\mathrm{U}$, the exact experimental value of $219 \mathrm{pm}$ is obtained. In pure goethite Fe-O distances of 194, $197\left(\mathrm{O}^{2-}\right), 209$ and $210 \mathrm{pm}\left(\mathrm{OH}^{-}\right)$(Table 1) were obtained, and with Lu substitution slightly elongated $\mathrm{Lu}-\mathrm{O}^{2-}$ distances of 212 and the $\mathrm{Lu}^{-} \mathrm{OH}^{-}$distances of 223-224 pm were found with $\mathrm{DFT}+\mathrm{U}$ and are comparable to reported experimental data for $\mathrm{Lu}$ incorporated within goethite (Finck et al. 2018). The increase in bond length from Fe-O to Lu-O is caused by the larger ionic radius (Shannon 1976) of $\mathrm{Lu}(\mathrm{III})\left({ }^{\mathrm{VI}} \mathrm{Lu}(\mathrm{III})=86 \mathrm{pm}\right.$ ) compared to $\mathrm{Fe}$ (III) $\left({ }^{\mathrm{VI}} \mathrm{Fe}(\mathrm{III})=65 \mathrm{pm}\right)$. 
The study was extended to determine the effect of substituting cations with differing ionic radii on the atomic structure of hematite and goethite. The larger lanthanide cations Gd(III) $\left({ }^{\mathrm{VI}} \mathrm{Gd}(\mathrm{III})=94 \mathrm{pm}\right)$ and $\mathrm{La}(\mathrm{III})\left({ }^{\mathrm{VI}} \mathrm{La}(\mathrm{III})=103 \mathrm{pm}\right)$ were used in the DFT and DFT $+\mathrm{U}$ calculations, replacing one $\mathrm{Fe}(\mathrm{III})$ per supercell by these $\mathrm{Ln}(\mathrm{III})$ ions and the effect on the calculated Ln-O distances was studied. In hematite the Gd-O distances increase to 216/236 pm and the La-O distances to $222 / 254 \mathrm{pm}$. Similarly, for goethite an increase in both Gd-O (217/230 pm) and La-O (224/240 pm) distances is found. These results reflect a general trend of increasing ionic radii from $\mathrm{Fe}(\mathrm{III})$ to $\mathrm{Lu}(\mathrm{III})$ and further to $\mathrm{Gd}(\mathrm{III})$ and $\mathrm{La}(\mathrm{III})$. However, the calculated increase for the longer $\mathrm{Ln}-\mathrm{O}$ distance over the series $\mathrm{Lu}$ (III) to $\mathrm{La}$ (III) is anomalously large in hematite compared to that for the shorter oxygen distances and for the longer goethite distance (Figure S5). The reason for this is not yet clear and subject to further investigations.

The agreement between calculated and experimental Lu-O and Fe-O bond lengths was very good for both systems, such that the corresponding energies can be considered well suited for a theoretical estimate of whether incorporation of $\mathrm{Lu}(\mathrm{III})$ is favoured in hematite or in goethite. Note that the Fe-O bond lengths in hematite and goethite are similar (Table 1), so that the sites available for Fe substitution within hematite or goethite are of same ionic size. Based on crystal chemistry, it can be predicted that substitution of $\mathrm{Lu}$ (III) for $\mathrm{Fe}(\mathrm{III})$ within both structures should thus be equally possible.

In order to determine which of both minerals is energetically favored for the incorporation of $\mathrm{Lu}(\mathrm{III})$, reaction (1) was considered with (Iron oxide/Fe) corresponding to either hematite or goethite and (Iron oxide/Lu) denotes the replacement of one Fe(III) by $\mathrm{Lu}(\mathrm{III})$ in either hematite or goethite. We used reaction (1) to determine the corresponding reaction energies $\Delta \mathrm{E}_{\text {Iron oxide/Ln }}$ $=\mathrm{E}_{\text {Iron oxide/Ln }}+\mathrm{E}_{\mathrm{Fe} 9(\mathrm{H} 2 \mathrm{O})}-\mathrm{E}_{\text {Iron oxide/Fe }}-\mathrm{E}_{\mathrm{Ln} \text { 9(H2O) }}$. This is the key parameter in order to judge where $\mathrm{Lu}(\mathrm{III})$ is more likely to become incorporated. Calculations yield for hematite $\Delta \mathrm{E}_{\mathrm{Hematit} / \mathrm{Lu}}=0.12 \mathrm{eV}$ and for goethite $\Delta \mathrm{E}_{\mathrm{Goethite} / \mathrm{Lu}}=0.20 \mathrm{eV}$. Since these energy differences are so similar, DFT calculations indicate that the incorporation of Lu(III) should be equally likely for hematite and goethite and not even a slight preference can be determined. However, ferrihydrite transformation into goethite or hematite can occur via a variety of different mechanisms that can be influenced by different parameters such as, e.g. temperature and $\mathrm{pH}$ (e.g., (Cornell and Schwertmann 1996)). Lu(III) was found incorporated predominantly within hematite upon ferrihydrite transformation at $70^{\circ} \mathrm{C}$ and $238 \mathrm{~h}$ (Dardenne et al. 2002) whereas in this study Lu substitutes for Fe within the goethite lattice upon aging for 12 years at room temperature. The difference in energy between both systems is very small, suggesting that 
differences in experimental parameters during the transformation, such as time and temperature, play an important role. The results from DFT calculations refer to systems at equilibrium and at $\mathrm{T}=0 \mathrm{~K}$ and hence do not account for transformation kinetics.

The energetics of incorporating the larger $\mathrm{Ln}(\mathrm{III})$ cations, $\mathrm{Gd}(\mathrm{III})$ and $\mathrm{La}(\mathrm{III})$, into the goethite and hematite lattices were considered in order to explore the dependence of Ln incorporation going across the series using reaction (1) and calculating the energies $\Delta \mathrm{E}_{\text {Iron oxide/Ln }}$ $=\mathrm{E}_{\text {Iron oxide/Ln }}+\mathrm{E}_{\mathrm{Fe} 9(\mathrm{H} 2 \mathrm{O})}-\mathrm{E}_{\mathrm{Iron} \text { oxide/Fe }}-\mathrm{E}_{\mathrm{Ln} 9(\mathrm{H} 2 \mathrm{O})}$.

The reaction energies of Gd(III) and La(III) were found theoretically to be more endothermic compared to $\mathrm{Lu}(\mathrm{III})$. The actual numbers for $\mathrm{Gd}(\mathrm{III})$ and $\mathrm{La}(\mathrm{III})$ are $\Delta \mathrm{E}_{\mathrm{Goethite} / \mathrm{Gd}}=1.08 \mathrm{eV}$ and $\Delta \mathrm{E}_{\text {Goethite/La }}=2.81 \mathrm{eV}$, respectively, for goethite, and $\Delta \mathrm{E}_{\mathrm{Hematite} / \mathrm{Gd}}=0.78 \mathrm{eV}$ and $\Delta \mathrm{E}_{\mathrm{Hematit} / \mathrm{La}}=$ $2.08 \mathrm{eV}$, respectively, for hematite. They are all more endothermic (larger) compared to Lu(III), thus indicating that increasing the substituting cation radius from $\mathrm{Lu}(\mathrm{III})$ to $\mathrm{La}$ (III) causes the incorporation in goethite or hematite to become less likely.

\section{Conclusion}

High efficiency STEM-EDXS, aberration corrected HAADF-STEM and DFT calculations were combined to study $\mathrm{Lu}$ associated hematite and goethite nanoparticle transformation products of 2-line ferrihydrite aged for 12 years in aqueous suspension in the presence of Lu(III). STEM-EDXS and atomic resolution HAADF-STEM imaging of acicular goethite crystals revealed the host Fe lattice sites to be partially replaced by $\mathrm{Lu}$, indicating substitutional incorporation of Lu into the crystal structure. In contrast, only marginal amounts of Lu seem to be associated with rhombohedral hematite nanoparticles. These results are in line with findings obtained by other experimental techniques (Finck et al. 2018). In the present study DFT calculations demonstrated that the energy difference between the reaction leading to $\mathrm{Lu}$ incorporation into goethite versus hematite is very small, suggesting both are about equally likely to occur. Additional DFT calculations revealed that lanthanide cations with larger ionic radii have a decreasing tendency for incorporation.

The outcomes of this study have implications for the disposal of nuclear waste. Results demonstrated that by aging at room temperature conditions and constant $\mathrm{pH}, \mathrm{Lu}$ can be structurally incorporated into goethite at Fe lattice sites following transformation of Lu(III) sorbed ferrihydrite, resulting in an immobilization into a stable crystalline form. Due to their similar chemistry, it can be anticipated that a similar immobilization mechanism could operate 
419 for trivalent actinides. However, DFT results suggest that incorporation of larger cations such as $\mathrm{Gd}(\mathrm{III})$ which has a size more comparable to that of e.g., the actinide Am(III) is less favorable

421 than for Lu(III). Yet, earlier work (Stumpf et al. 2006) suggested that partial incorporation of 422 Am(III) into ferrihydrite transformation products operates. Long-term experiments with Gd(III), 423 similar to that performed in this study with $\mathrm{Lu}(\mathrm{III})$, would thus be needed to conclude on the 424 possible stability of the incorporated Am species in iron corrosion phases in a deep repository. 425 Additional experimental long-term aging studies would also be needed to consider the effect of 426 different chemical environments on Ln/An incorporation. Data presented in this study also clearly demonstrate that high efficiency STEM-EDXS and atomic resolution HAADF-STEM 428 imaging are likely to be key tools in any such future investigations providing unrivaled 429 capabilities for detecting and characterizing at the atomic level, low concentrations of 430 lanthanides associated with iron-based materials. This type of detailed structural understanding 431 of aged materials is vital for demonstrating the long-term safe disposal of RNs in nuclear waste 432 repositories.

\section{Acknowledgements}

435 The authors would like to thank D. Wang at Karlsruhe Institute of Technology for useful discussions. S.J.H. acknowledges support from EPSRC (EP/M010619/1 and EP/K016946/1) and NNUMAN. 

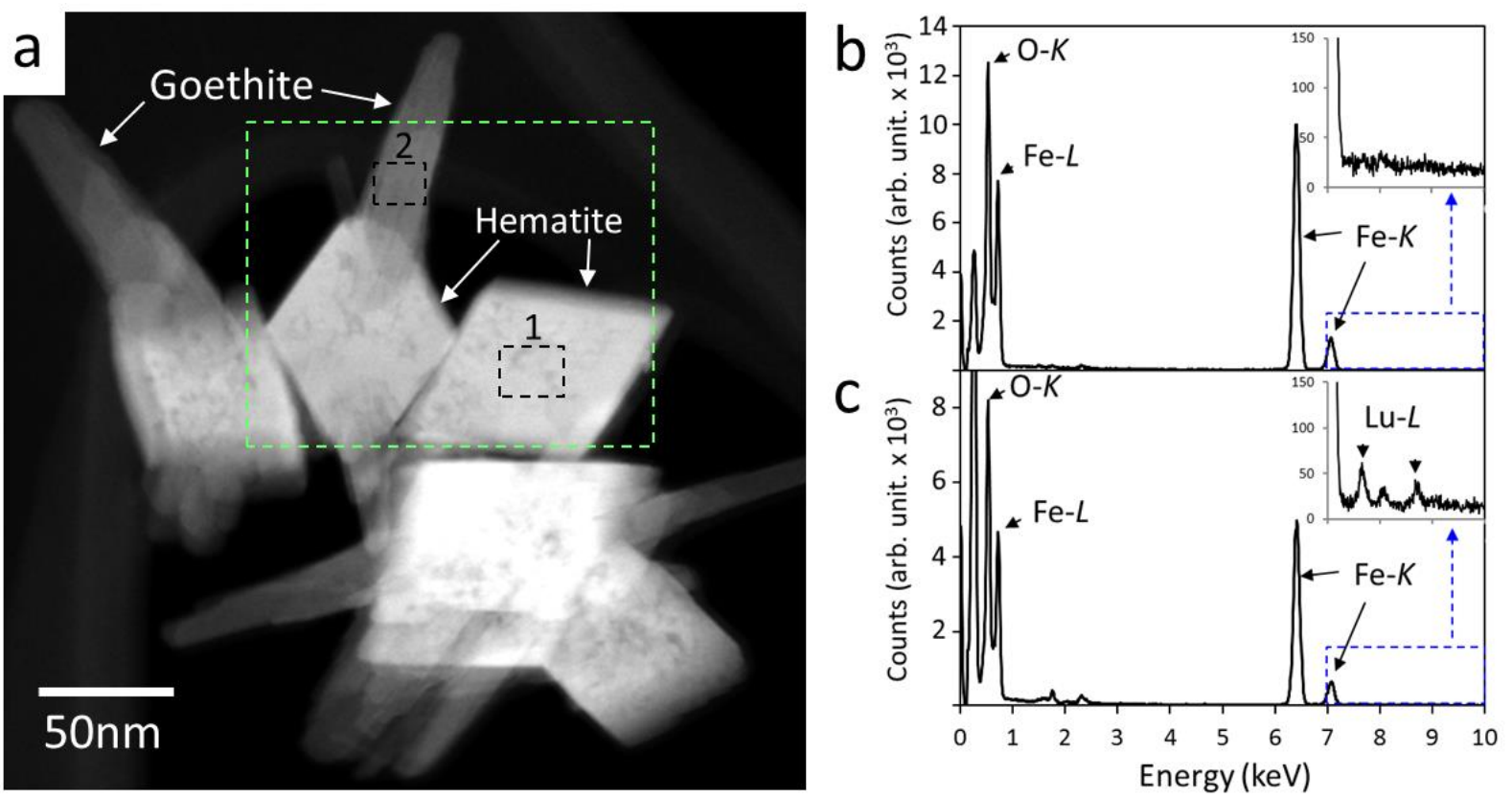

440

$441 \quad$ Figure 1

442 a) HAADF-STEM image taken from hematite and goethite. b) Summed EDX spectrum 443 obtained from Area 1 (hematite crystal). c) Summed EDX spectrum obtained from Area 2 444 (goethite crystal). The insets show an enlargement of the high-energy region, where Lu $L$ 445 emission lines are expected. 

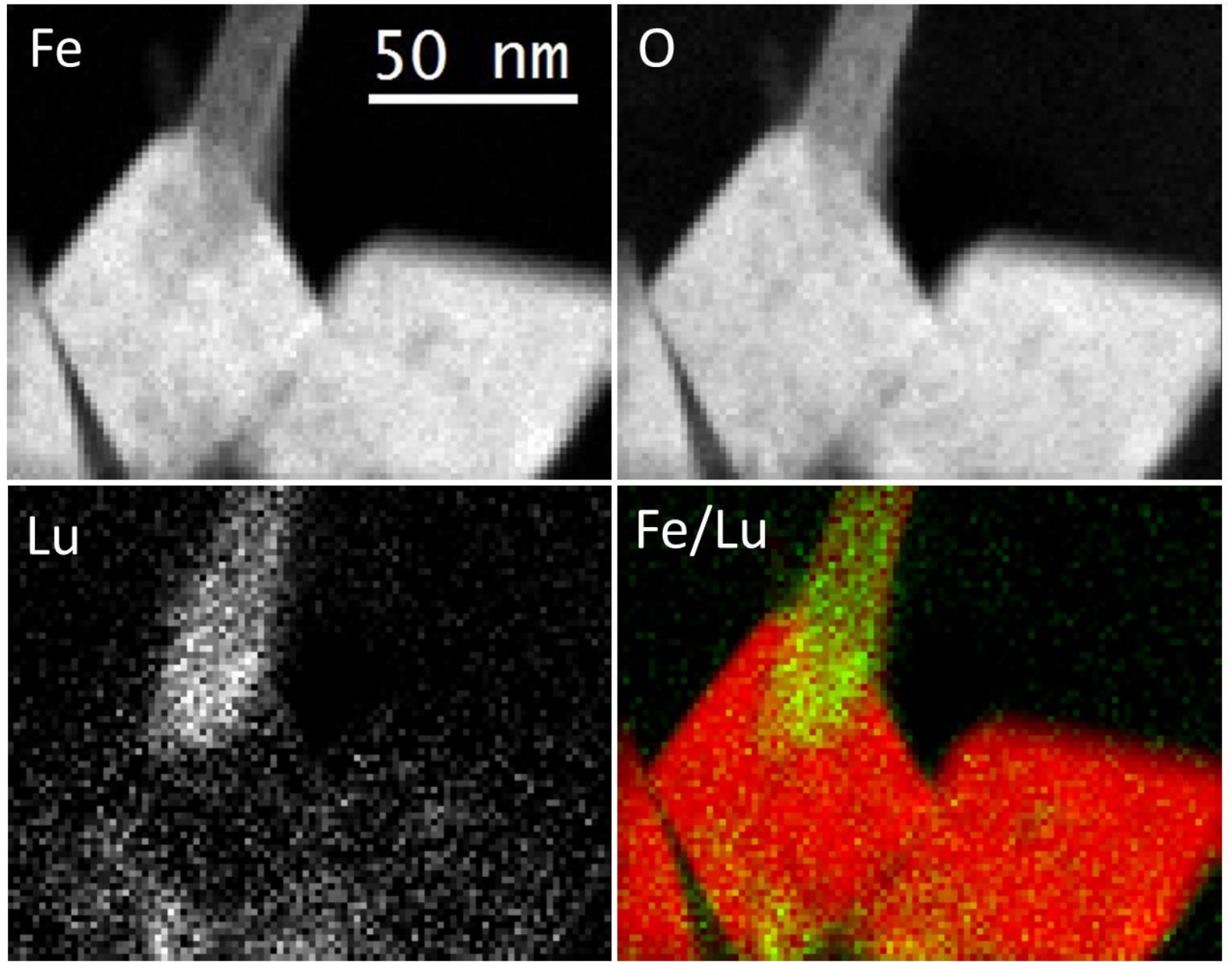

\section{$\mathrm{Fe} / \mathrm{Lu}$}

446

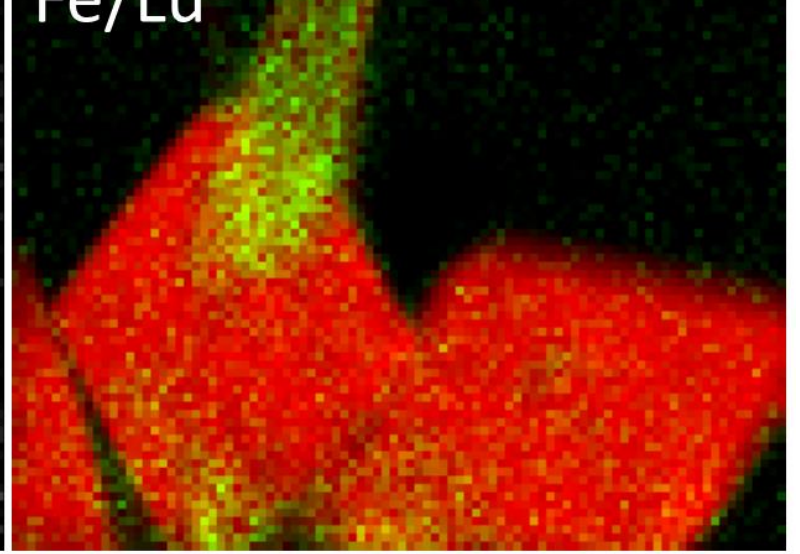

Figure 2

449 EDX spectrum images of hematite particles and goethite needle. Images are taken from a part 450 of the area in Figure 1. Fe and Lu distributions in the overlapped image ( $\mathrm{Fe} / \mathrm{Lu})$ are indicated 451 by red and light green, respectively. 

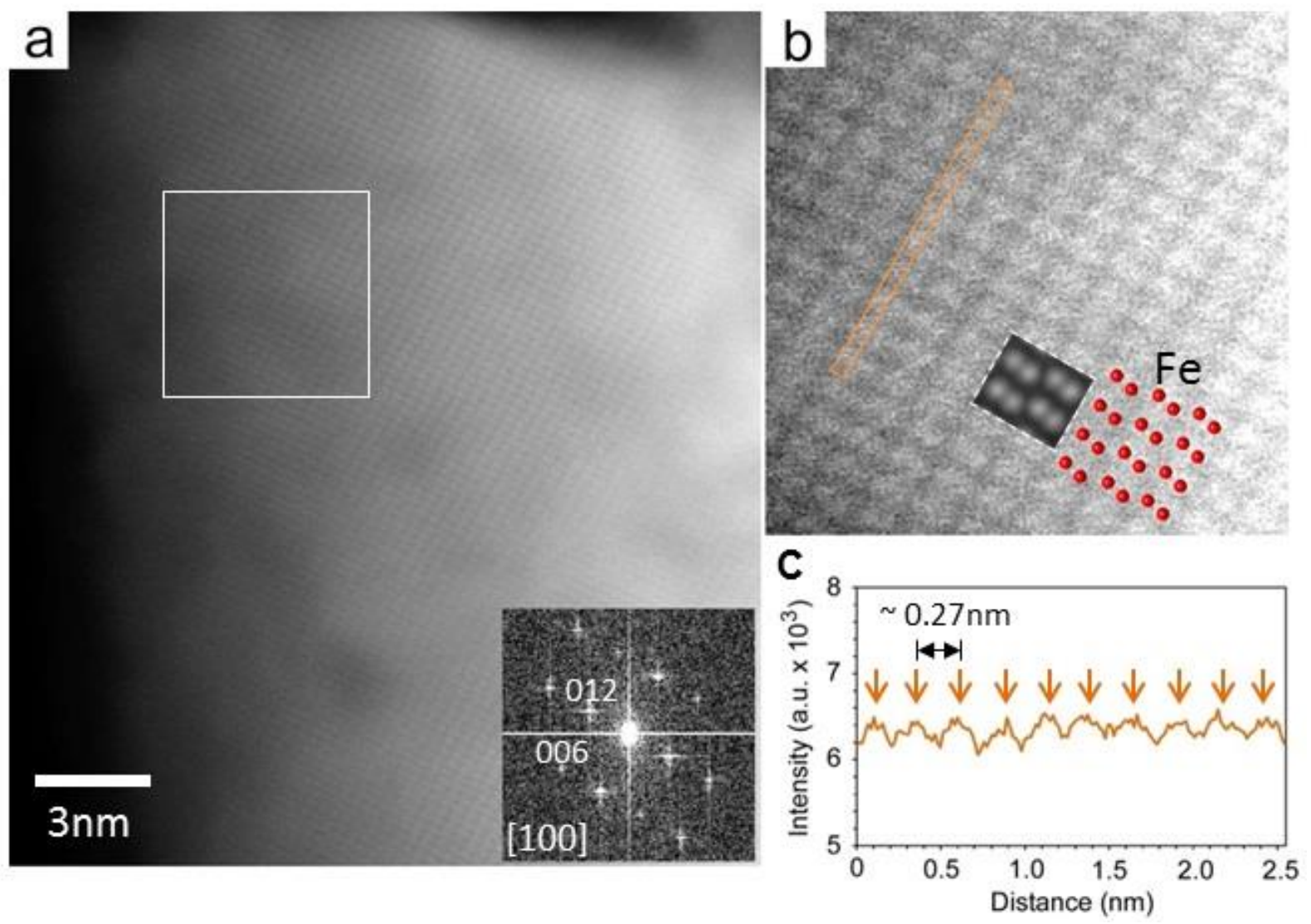

\section{$454 \quad$ Figure 3}

455 Atomic resolution HAADF-STEM image of hematite. a) HAADF-STEM image oriented along 456 [100]. b) Enlarged view of the area indicated by a white square in a). c) Intensity profile 457 obtained from the orange stripe region shown in b). Periodic variations associated with Fe 458 atomic columns are indicated by orange arrows. In b) the corresponding simulated HAADF459 STEM image is shown in the area marked by a dashed line. 

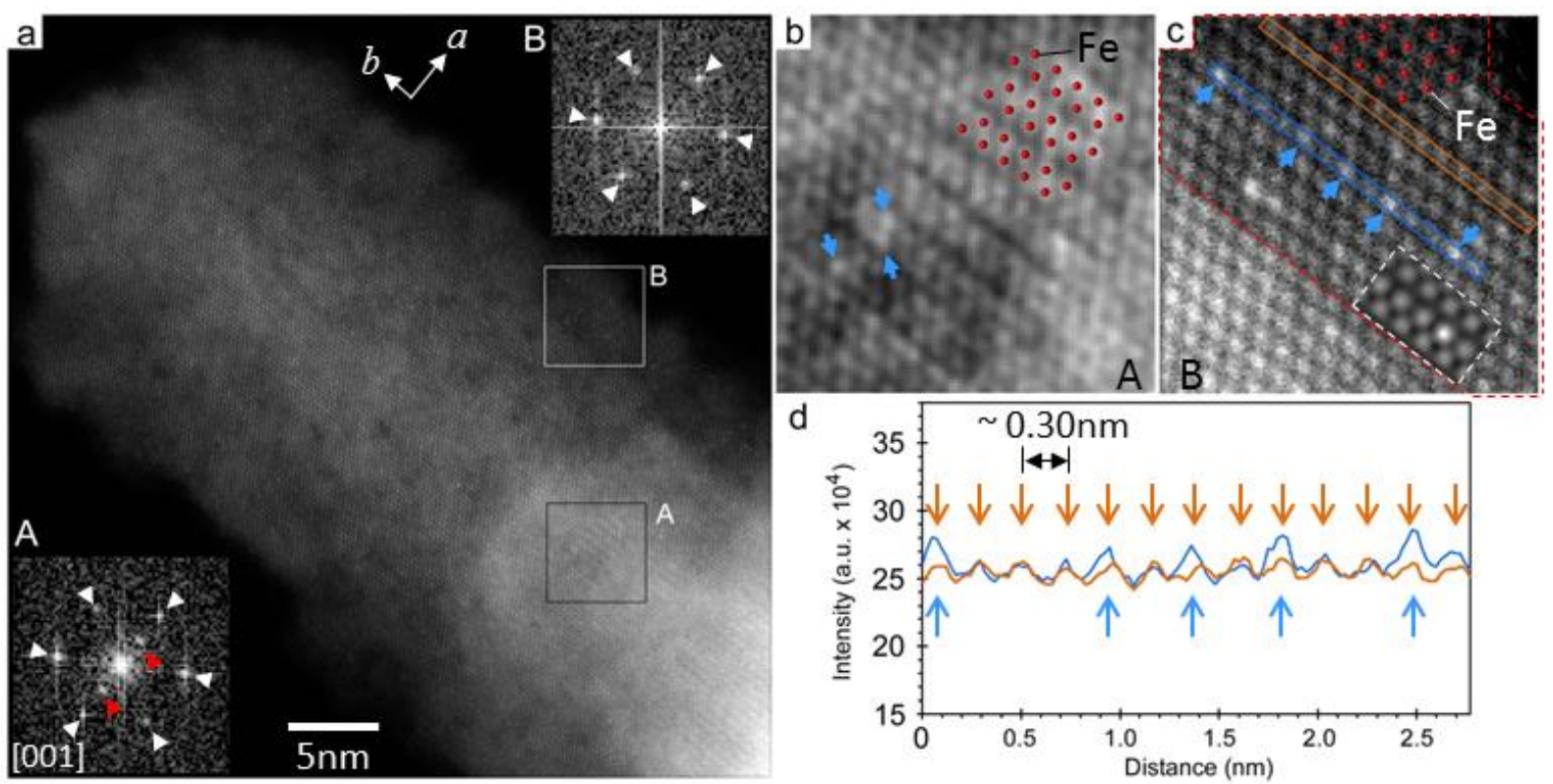

462

\section{Figure 4}

464 Atomic resolution HAADF-STEM imaging of a goethite nanoparticle. a) HAADF-STEM image with the particle viewed along [001]. The insets depict Fourier transforms taken from

466 areas indicated A and B. b) Enlarged view of area A. c) Enlarged view of area B. d) Intensity 467 distributions obtained from regions indicated by the blue and orange rectangles shown in c). 468 The periodicity of $\sim 0.30 \mathrm{~nm}$ (indicated by orange arrows) in d) is consistent with the interatomic 469 distance between a pair of Fe atoms along the [010] direction of goethite. The blue arrows 470 indicate isolated columns of higher intensity, associated with the presence of $\mathrm{Lu}$. In c) the 471 simulated HAADF-STEM image of Lu atoms substitutionally incorporated in goethite is shown 472 in the area marked with a dashed line. 
(a)
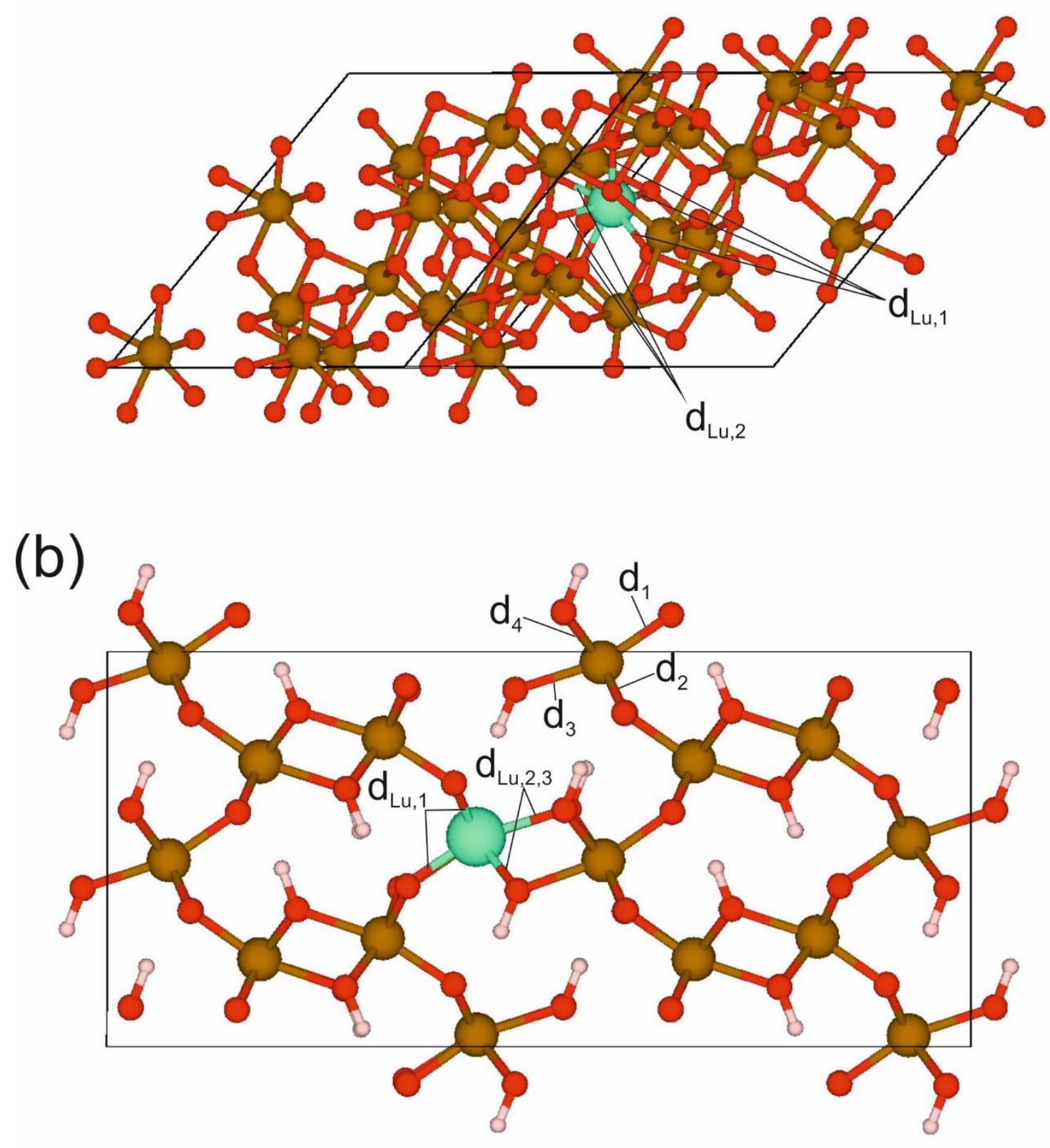

473

$474 \quad$ Figure 5

475 Supercells used for DFT calculations of (a) hematite and (b) goethite. Fe: brown, O: red, H: 476 white, Lu: green. $d_{i}$ refer to Fe-O distances listed in Table 1. 


\begin{tabular}{cccc}
\hline Parameter & Experiment & DFT & DFT+U \\
\hline & Maslen et al. 1994 & This work & This work \\
$\boldsymbol{a}, \boldsymbol{b}, \boldsymbol{c}$ & 542 & 551 & 548 \\
$\boldsymbol{\alpha}, \boldsymbol{\beta}, \boldsymbol{\gamma}$ & 55.3 & 54.5 & 55.1 \\
$\mathbf{F e}-\mathbf{O}$ & 198 & 194 & 197 \\
$\mathbf{F e}-\mathbf{O}$ & 206 & 217 & 212 \\
\hline
\end{tabular}

\section{Goethite}

Hazemann et al. 1991

This work

1001

302

466

189

198

$\mathrm{Fe}-\mathrm{OH}\left(d_{3}\right)$

$\mathrm{Fe}-\mathrm{OH}\left(d_{4}\right)$
195

207

210
212

214
197

This work

995

302

455

194

209

210

478

479

Table 1

480 Comparison between calculated structural parameters and available experimental structural 481 data for the rhombohedral unit cell of hematite and the orthorhombic goethite (Maslen et al. 482 1994; Hazemann et al. 1991). $d_{i}$ refer Fe-O distances shown in Figure 5b. All distances are 483 given in pm and angles in degrees $\left(^{\circ}\right)$. 


\begin{tabular}{ccc}
\hline $\boldsymbol{d}$ & Experiment & DFT + U \\
& Hematite & \\
& Dardenne et al. 2002 & This work \\
Lu-O & $219\left(\mathrm{~d}_{\mathrm{Lu}, 1}\right)$ \\
& & $226\left(\mathrm{~d}_{\mathrm{Lu}, 2}\right)$ \\
Lu-Fe & 309 & 305 \\
Lu-Fe & 342 & 342 \\
Lu-Fe & 389 & 378 \\
\hline
\end{tabular}

\section{Goethite}

Finck et al. 2018

This work

$212\left(\mathrm{~d}_{\mathrm{Lu}, 1}\right)$

Lu-O

220

$223,224\left(d_{\mathrm{Lu}, 2,3}\right)$

Lu-Fe 307

Lu-O 328

$\begin{array}{lll}\text { Lu-Fe } & 349 & 350\end{array}$

486 Table 2

487 Comparison between experimental and calculated values for the $\mathrm{Lu}-\mathrm{O}$ and $\mathrm{Lu}-\mathrm{Fe}$ distances in 488 hematite and goethite. All distances are given in pm. 


\section{References}

Baleeiroa A, Fiol S, Otero-Fariñaa A, Anteloa J (2018) Surface chemistry of iron oxides formed by neutralization of acidic mine waters: Removal of trace metals. Applied Geochem, 89:129-137. doi.org/10.1016/j.apgeochem.2017.12.003

Batson PE, Dellby N, Krivanek OL (2002) Sub-angstrom resolution using aberration corrected electron optics. Nature 418:617-620. doi: 10.1038/nature00972

Blöchl PE (1994) Projector augmented-wave method. Phys Rev B 50:17953-17979. doi.org/10.1103/PhysRevB.50.17953

Bouby M, Geckeis H, Manh TN, Yun JI, Dardenne K, Schäfer T, Walter C, Kim JI (2004) Laser-induced breakdown detection combined with asymmetrical flow field-flow fractionation: application to iron oxi/hydrooxide colliod characterization. $\mathrm{J}$ Chromatogr A 1040:97-104. doi.org/10.1016/j.chroma.2004.03.047

Brydson R, Brown A, Benning LG, Livi K (2014) Analytical transmission electron microscopy. Reviews in Mineralogy \& Geochemistry, 78:219-269. doi.org/10.2138/rmg.2014.78.6

Cornell RM, Mann S, Skarnulis JA (1983) A high-resolution electron microscopy examination of domain boundaries in crystals of synthetic goethite. J Chem Soc Faraday Trans 79:2679-2684. doi: 10.1039/F19837902679

Cornell RM, Schwertmann U. (1996) The Iron Oxides: Structure, Properties, Reactions, Occurrences and Uses. VCH, Weinheim, Germany. doi:10.1002/3527602097

Dardenne K, Schäfer T, Denecke MA, Rothe J, Kim, JI (2001) Identification and characterization of sorbed lutetium species on 2-line ferrihydrite by sorption data modeling, TRLFS and EXAFS. Radiochim Acta 89:469-479. doi: 10.1524/ract.2001.98.7.469

Dardenne K, Schäfer T, Lindqvist-Reis P, Denecke MA, Plaschke M, Rothe J, Kim JI (2002) Low temperature XAFS investigation on the Lutetium binding changes during the 2line ferrihydrite alteration process. Environ Sci Technol 36:5092-5099. doi: 10.1021/es025513f

Deglmann P, May K, Furche F, Ahlrichs R (2004) Nuclear second analytical derivative calculations using auxiliary basis set expansions. Chem Phys Letters 384:103-107. doi.org/10.1016/j.cplett.2003.11.080

Denecke MA (2006) Actinide speciation using X-ray absorption fine structure spectroscopy. Coord Chem Re. 250:730-754. doi.org/10.1016/j.ccr.2005.09.004

Duff MC, Coughlin JU, Hunter DB (2002) Uranium co-precipitation with iron oxide minerals. Geochim Cosmochim Acta 66:3533-3547. doi.org/10.1016/S0016-7037(02)00953-5

Eichkorn K, Treutler O, Öhm H, Häser M, Ahlrichs R (1995) Auxiliary basis sets to approximate Coulomb potentials. Chem Phys Lett 242:652-660. doi.org/10.1016/0009-2614(95)00621-A 
Eichkorn K, Weigend F, Treutler O, Ahlrichs R (1997) Auxiliary basis sets for main row atoms and transition metals and their use to approximate coulomb potentials. Theor. Chem Acc 97:119-124. doi.org/10.1007/s002140050244

Finck N, Bouby M, Dardenne K (2018) Fate of Lu(III) sorbed on 2-line ferrihydrite at pH 5.7 and aged for 12 years at room temperature. I: Insights from ICP-OES, XRD, ESEM, AsFlFFF/ICP-MS and EXAFS spectroscopy. Environ Sci Pollut Res doi.org/10.1007/s11356-018-1314-X

Finck N, Drot R, Lagarde G, Mercier-Bion F, Catalette H, Simoni E (2008) Temperature effects on the interaction mechanism between $\mathrm{U}(\mathrm{VI})$ and $\mathrm{Eu}(\mathrm{III})$ and $\mathrm{ZrP}_{2} \mathrm{O}_{7}$ : experiment and modelling. Radiochim Acta 96:11-21. doi: 10.1524/ract.2008.1459

Finck N, Schlegel M, Bosbach D (2009) Sites of Lu(III) Sorbed to and coprecipitated with hectorite. Environ Sci Technol 43(23):8807-8812. doi: 10.1021/es901940v

Geckeis H, Lützenkirchen J, Polly R, Rabung T, Schmidt M (2013) Mineral-water interface reactions of actinides. Chem Rev 113:1016-1062. doi: 10.1021/cr300370h

Gorski CA, Fantle MS (2017) Stable mineral recrystallization in low temperature aqueous systems: A critical review. Geochim Cosmochim Acta 198: 439-465. doi.org/10.1016/j.gca.2016.11.013

Hazemann JL, Bérar J, Manceau A (1991) Rietveld studies of the aluminium-iron substitution in synthetic goethite. Materials Science Forum 79-82:821-826. doi: 10.4028/www.scientific.net/MSF.79-82.821

Hohenberg P, Kohn W (1964) Inhomogeneous Electron Gas. Phys Rev 136:B864-B871. doi.org/10.1103/PhysRev.136.B864

Kohn W, Sham LJ, (1965) Self-consistent equations including exchange and correlation effects. Phys Rev 140:A1133-A1138. doi.org/10.1103/PhysRev.140.A1133

Kresse G, Furthmüller J (1996) Efficient iterative schemes for ab initio total-energy calculations using a plane-wave basis set. Phys Rev B 54:11169-11186. doi.org/10.1103/PhysRevB.54.11169

Kresse G, Furthmüller J (1996) Efficiency of ab-initio total energy calculations for metals and semiconductors using a plane-wave basis set. Comput Mater Sci. 6:15-50. doi.org/10.1016/0927-0256(96)00008-0

Kresse G, Hafner J (1993) Ab initio molecular dynamics for open-shell transition metals. Phys. Rev. B 48:13115-13118. doi.org/10.1103/PhysRevB.48.13115

Kresse G, Joubert D (1999) From ultrasoft pseudopotentials to the projector augmented-wave method. Phys Rev B 59:1758-1775. doi.org/10.1103/PhysRevB.59.1758

Kresse G, Marsman M, Furthmüller J, VASP the GUIDE (2016) Available at: https://cms.mpi.univie.ac.at/vasp/vasp/vasp.html.

Latta D, Gorski C, Boyanov M, O’Loughlin E, Kemner K, Scherer MM (2012) Influence of magnetite stoichiometry on $\mathrm{U}^{\mathrm{VI}}$ reduction. Environ Sci Technol 46(2):778-786. $10.1021 /$ es2024912 
Marshall TA, Morris K, Law GTW, Livens FF, Mosselmans JFW (2014) Incorporation of uranium into hematite during crystallization from ferrihydrite. Bots $\mathrm{P}$, Shaw S. Environ Sci Technol 48:3724-3731. dx.doi.org/10.1021/es500212a

Maslen E., Streltsov VA, Streltsova NR, Ishizawa N (1994) Synchrotron X-ray study of the electron density in $\alpha-\mathrm{Fe} 2 \mathrm{O} 3$. Acta Cryst B 50:435-441. doi.org/10.1107/S0108768194002284

Michel MF, Ehm L, Antao SM, Lee PL, Chupas PJ, Liu G, Strongin DR, Schoonen MAA, Phillips BL, Parise JB (2007) The structure of ferrihydrite, a nanocrystalline material. Science 316: 1726-1729. doi: 10.1126/science.1142525

Nagano T, Mitamura H, Nakayama S, Nakashima S (1999) Formation of geothite and hematite from neodymium-containing ferryhidrite suspensions. Clays Clay Min 47:748-754. 10.1346/CCMN.1999.0470609

Nellist PD, Pennycook SJ (1999) Incoherent imaging using dynamically scattered coherent electrons. Ultramicroscopy, 78:111-124. doi.org/10.1016/S0304-3991(99)00017-0

Newbury DE. (2005) The new X-ray mapping: Applying the silicon drift detector (SDD) for $\mathrm{X}$-ray spectrometry and spectrum imaging with output count rates above $100 \mathrm{kHz}$. Microsc Microanal 11:1328-1329. doi: 10.1017/S1431927605500540

Novikov AP, Kalmykov SN, Utsunomiya S, Ewing RC, Horreard F, Merkulov A, Clark SB, Tkachev VV, Myasoedov BF (2006) Colloid transport of plutonium in the far-field of the Mayak production association, Russia. Science 314:638-641. doi.org/10.1126/science. 1131307

Okuno H, Rouviere JL, Jouneau PH, Bayle-Guillemaud P, Daudin B (2010) Visualization of TM dopant atoms diffused out of GaN quantum dots. Appl Phys Lett, 96:251908-1251908-3 doi.org/10.1063/1.3455893

O'Loughlin E, Kelly S, Cook R, Csencsits R, Kemner K (2003) Reduction of uranium (VI) by mixed iron (II)/iron (III) hydroxide (green rust): formation of $\mathrm{UO}_{2}$ nanoparticles. Environ Sci Technol 34(4):721-727. doi: 10.1021/es0208409

Perdew JP, Burke K, Ernzerhof M (1996) Generalized gradient approximation made simple. Phys Rev Lett 77:3865-3868. doi: 10.1103/PhysRevLett.77.3865

Powell BA, Dai Z, Zavarin M, Zhao P, Kersting AB (2011) Stabilization of plutonium nanocolloids by epitaxial distortion on mineral surfaces. Environ Sci Technol 45:26982703. doi: $10.1021 /$ es 1033487

Raiswell R (2011) Iron Transport from the continents to the open ocean: The agingrejuvenation cycle. Elements 7:101-106. doi.org/10.2113/gselements.7.2.101

Rollmann G, Rohrbach P, Entel P, Hafner J (2004) First-principles calculation of the structure and magnetic phases of hematite. Phys Rev B 69:165107-1-165107-12.

Schäfer A, Horn H, Ahlrichs R (1992) Fully optimized contracted gaussian basis sets for atoms Li to Kr. J Chem Phys 97:2571-2577. doi.org/10.1103/PhysRevB.69.165107 
Schlossmacher P, Klenov DO, Freitag B, von Harrach S, Steinbach A (2013) Nanoscale chemical compositional analysis with an innovative S/TEM-EDX system. Microscopy and Analytical Nanotechnology (November), S5-S8.

Schwertmann U, Cornell RM (1991) Iron Oxides in the Laboratory. Preparation and Characterization. VCH Verlagsgesellschaft mbH: Weinheim, Germany; VCH Publishers, Inc.: New York, USA. doi: 10.1002/9783527613229

Shannon RD (1976) Revised effective ionic radii and systematic studies of interatomic distances in halides and chalcogenides. Acta Cryst A32:751-767. doi.org/10.1107/S0567739476001551

Skomurski FN, Rosso KM, Krupka KM, McGrail BP (2010) Technetium incorporation into hematite (a-Fe2O3). Envion Sci Technol 44:5855-5861. doi: 10.1021/es100069x

Smith FN, Taylor C, Um W, Kruger AA (2015) Technetium incorporation into goethite (aFeOOH): An atomic-scale investigation. Environ Sci Technol 49:13699-13707.

Stegemeier JP, Reinsch BC, Lentini CJ, Dale JG, Kim CS (2015) Aggregation of nanoscale iron oxyhydroxides and corresponding effect on metal uptake, retention, and speciation: II. Temperature and time. Geochim Cosmochim Acta 148:113-129. doi: 10.1016/j.gca.2014.08.031

Stumpf S, Stumpf T, Dardenne K, Hennig C, Foerstendorf H, Klenze R, Fanghänel T (2006) Sorption of Am(III) onto 6-line-ferrihydrite and its alteration products: Investigations by EXAFS. Environ Sci Technol 40:3522-3528. doi: 10.1021/acs.est.5b03354

Suenaga K, Okazaki T, Okunishi E, Matsumura S (2012) Detection of photons emitted from single erbium atoms in energy-dispersive X-ray spectroscopy. Nat. Photonics 6:545548. doi: 10.1038/nphoton.2012.148

Tan X, Fang M, Wang X (2010) Sorption speciation of lanthanides/actinides on minerals by TRLFS, EXAFS and DFT studies: A review. Molecules, 15:8431-8468. doi:10.3390/molecules15118431

Tertre E, Berger G, Simoni E, Castet S, Giffaut E, Loubet M, Catalette H (2006) Europium retention onto clay minerals from 25 to $150^{\circ} \mathrm{C}$. Experimental measurements, spectroscopic features and sorption modelling. Geochim Cosmochim Acta 70: 4563 4578. doi: 10.1016/j.gca.2006.06.1568

Treutler O, Ahlrichs R (1995) Efficient molecular numerical integration schemes. J Chem Phys 102:346-354. doi.org/10.1063/1.469408

Tunega D (2012) Theoretical study of properties of goethite $(\alpha-\mathrm{FeOOH})$ at ambient and highpressure conditions. J Phys Chem C, 116:6703-6713. doi: dx.doi.org/10.1021/jp2091297

TURBOMOLE, TURBOMOLE V7.0 (2015) A development of University of Karlsruhe and Forschungszentrum Karlsruhe GmbH, 1989-2007, TURBOMOLE GmbH, since 2007; available from http://www.turbomole.com. 
Um W, Chang HS, Icenhower JP, Lukens WW, Serne RJ, Qafoku NP, Westsik JH, Buck EC, Smith SC (2011) Immobilization of 99-technetium (VII) by Fe(II)-goethite and limited reoxidation. Environ Sci Technol 45:4904-4913. doi: 10.1021/es104343p

Utsunomiya S, Ewing RC (2003) Application of high-angle annular dark field scanning transmission electron microscopy, scanning transmission electron microscopy-energy dispersive X-ray spectrometry, and energy-filtered transmission electron microscopy to the characterization of nanoparticles in the environment. Environ Sci Technol 37:786-791. doi: 10.1021/es026053t

Varela M, Lupini AR, van Benthem K, Borisevich AY, Chisholm MF, Shibata N, Abe E, Pennycook SJ (2005) Materials characterization in the aberration-corrected scanning transmission electron microscope. Annu Rev Mater Res 35:539-569. doi.org/10.1146/annurev.matsci.35.102103.090513

von Arnim M, Ahlrichs R (1999) Geometry optimization in generalized natural internal Coordinates. J Chem Phys 111:9183-9190. doi.org/10.1063/1.479510

Voyles PM, Muller DA, Grazul JL, Citrin PH, Gossmann HJ (2002) Atomic-scale imaging of individual dopant atoms and clusters in highly n-type bulk Si. Nature, 416:826-829. doi:10.1038/416826a

Wenzel MJ, Steinle-Neumann G (2007) Nonequivalence of the octahedral sites of cubic $\mathrm{Fe}_{3} \mathrm{O}_{4}$ magnetite. Phys Rev B, 75:214430. doi: 10.1103/PhysRevB.75.214430.

Xiu W, Guo H, Zhou X, Wanty RB, Kersten M (2018) Change of arsenite adsorption mechanism during aging of 2-line ferrihydrite in the absence of oxygen. Applied Geochem, Part B 88:149-157. doi.org/10.1016/j.apgeochem.2017.08.001 